\title{
On the formation of a waterproofing shell around the underground structure lining in watered ground
}

\author{
Andrey Uglyanitsa ${ }^{1 *}$ \\ ${ }^{1}$ T.G. Gorbachev Kuzbass State Technical University, 28 Vesennyaya, Kemerovo, the Russian \\ Federation
}

\begin{abstract}
To prevent the filtration of groundwater into the used underground structure in operation through its lining, it is proposed to make two waterproofing shells by the underground method around the outer surface of the lining of an underground structure; the upper one is made of the soil mass compacted by cementation with reduced water permeability and the lower one is made of the silicate cement. To make the upper shell, boreholes are drilled from an underground structure through its lining and the cement mortar is alternately injected through them into the watered ground providing its hydraulic fracturing; and to make the lower shell, injection pipes with a diameter of 102-152 $\mathrm{mm}$ are installed between the boreholes in the lining flush with its outer surface, the silicate cement mortar is alternately injected into the injection pipes, an incipient crack is created between the outer surface of the lining and the ground under the action of the mortar injection pressure on the ground opposite the injection pipe, an incipient crack is hydraulically extended along the contact of the lining with the ground and filled with the silicate cement mortar until refusal to absorb it. To determine the optimal parameters of the hydraulic separation process, tests were carried out on the laboratory table simulator.
\end{abstract}

\section{Introduction}

During the use of underground structures located in watered grounds, over time, physical wear of the underground structure lining occurs and the continuity of its waterproofing coating is disturbed. As a result, groundwater, filtering through a worn-out waterproofing coating and lining, penetrates into the underground structure, impedes its normal use and has a corrosive effect on the underground structure and the equipment located in it.

To replace worn-out waterproofing of the used underground structure located at a depth of up to 7-10 m, in practice, an open cut repair method is widely used, which includes excavation of soil from the earth's surface down to an underground structure with exposure of its lining, removal of damaged waterproofing, application of a new waterproofing shell to the outer surface lining and backfilling of an excavation over an underground structure [1]. At the same time, in unstable watered grounds, the soil mass to be excavated is preliminarily supported with a "pile planking" or "diaphragm wall" and, if necessary, the walled soil mass is unwatered $[2,3,4]$.

*Corresponding author: uav@,kuzstu.ru 
The disadvantage of this technology for replacing the waterproofing shell of an underground structure is the high cost and labor-intensity of the excavation and backfilling, walling and dewatering of the soil mass, which grow with an increase in the depth of an underground structure. In addition, this technology cannot be used when underground utilities or surface capital structures are located above an underground structure, as well as when an underground structure is located at a significant depth.

When the depth of an underground structure is more than 7-10 $\mathrm{m}$, in order to prevent the penetration of groundwater into an underground structure through its worn-out lining, in practice, the underground waterproofing method is used, which includes drilling wells in the ground through the lining of an underground structure, placing injectors in them and alternating injection of the cement mortar under pressure through wells into the ground providing its hydraulic fracturing $[5,6,7,8,9,10]$. After fracturing the ground with the cement mortar, the soil is compressed by expanding hydraulic fracturing cracks due to the supply of the cement mortar, increasing the density and strength of the ground and, as a result, its water resistance within the length of the wells.

However, as the practical experience of using the watered ground cementation shows, the injection of the cement mortar through wells into the watered ground providing its hydraulic fracturing does not allow eliminating the pore water permeability of the ground around an underground structure and, as a consequence, completely preventing the penetration of groundwater into the used underground structure through its lining. The purpose of the study is to develop a technology for restoring waterproofing of the used underground structure in the watered ground by an underground method to prevent the penetration of groundwater into the used underground structure through its lining.

For this purpose, the following engineering and technological solutions are proposed. The wells are drilled from an underground structure through its lining into the watered ground, injectors are placed in them, the cement mortar is alternately injected through the wells into the ground under pressure providing its hydraulic fracturing and the cement mortar is injected until refusal to absorb it. After cementation of the ground through the wells, injection pipes are installed from an underground structure into the lining between wells flush with the outer surface of the lining, the silicate cement mortar is alternately injected into each injection pipe, an incipient crack between the outer surface of the lining and the ground is created under the action of the mortar injection pressure on the ground opposite the injection pipe, the incipient crack is hydraulically extended along the contact of the lining surface with the ground and filled with the silicate cement mortar until refusal to absorb it.

After injecting the cement mortar through the wells into the ground, providing its hydraulic fracturing, hydraulic separation of the outer surface of the lining of an underground structure from the ground and filling the hydraulic separation cracks with cement-silicate mortar, two waterproofing shells are formed around an underground structure, the upper one made of the soil mass compacted by cementation with artificially reduced water permeability and the lower one is made of the silicate cement.

At present, technologies and methods for determining the parameters of hydraulic fracturing of rocks and coal mass have been developed [11, 12, 13, 14, 15]. These technologies are not suitable for hydraulic separation of the lining of an underground structure from the overlying soil, since they provide for the hydraulic fracturing of a homogeneous medium (rock or coal), and in this case, dissimilar physical media (concrete and soil) are hydraulically separated along their contact zone.

The radius of the mortar propagation from the injection pipe along the hydraulic fracture and the thickness of the silicate cement shell between the lining and the ground (the magnitude of the hydraulic separation crack opening) will depend on the composition and properties of the silicate cement mortar, soil properties, final pressure, conditions of the 
cement-silicate mortar injection, and other factors. It is extremely difficult to study this multifactorial process by building its mathematical model, therefore, in this case, the most preferred research method is the method of physical simulation of the process of hydraulic separation of the lining from the watered ground on an experimental laboratory table simulator.

For this purpose, on the basis of the methods of the theory of similarity and modeling, an experimental facility was developed with the table simulator that simulates the process of hydraulic separation of the lining of an underground structure from the watered ground (Fig. 1 and Fig. 2).

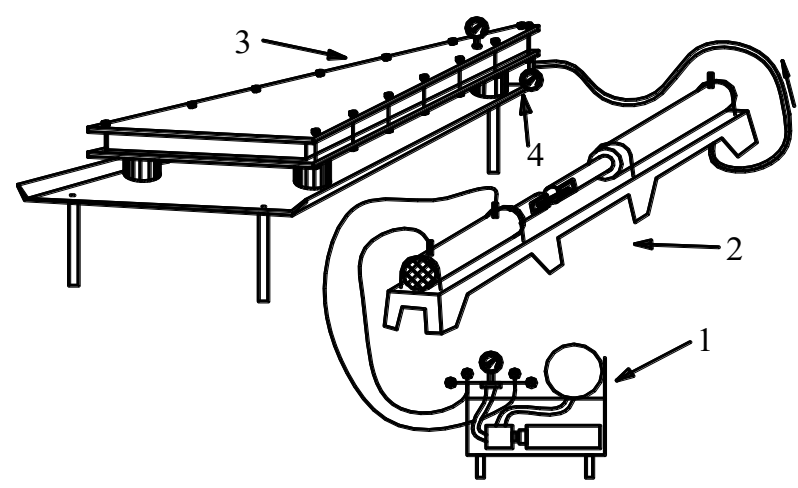

Fig. 1. Experimental facility layout: 1 - oil pumping station; 2 - hydraulic cylinder system for mortar injection; 3 - table simulator; 4 - injection pipe.

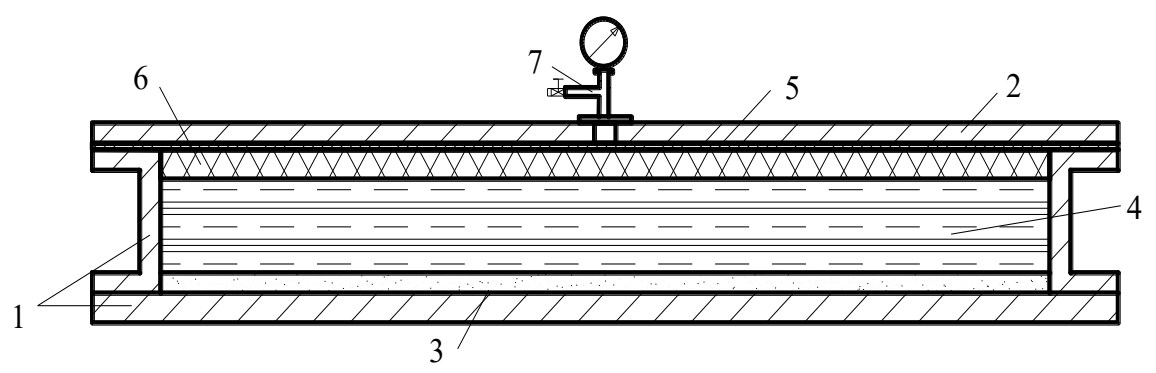

Fig. 2. Cross section of the table simulator: 1 - body; 2 - cover; 3 - concrete simulating the underground structure lining; 4 - soil above the structure lining; 5 - rubber diaphragm; 6 - inflatable rubber bag; 7 - nipple with pressure gauge for inflating the bag.

The table simulator body is made in the form of a sector with an apex angle of $11^{\circ}$. The simulator makes it possible to simulate hydraulic separation at a distance of up to 2.5 $\mathrm{m}$ from the well.

A series of experiments on hydraulic separation of the lining of an underground structure from watered ground was carried out on the experimental table simulator. Hydraulic separation was carried out with the silicate cement mortar with a cement-water mass ratio $\mathrm{C}: \mathrm{W}=1: 0.5,1: 0.75$, and $1: 1$. The sodium silicate amount in solutions was $1,3,5$, and $7 \%$ by weight of the cement. The temperature of the mortar was $10-12^{0} \mathrm{C}$. Water-saturated clay with a density of $\rho=2 \cdot 10^{3} \mathrm{~kg} / \mathrm{m}^{3}$ was used as a ground above the lining in the model. The experiments were carried out at a ground pressure on the lining $P_{\mathrm{\Gamma}}$ of $0.10,0.15$, and 0.20 $\mathrm{MPa}$, which corresponded to the depth of the underground structure location - 5.0, 7.5, and 
$10 \mathrm{~m}$. The value of the final pressure of the mortar injection into the injection pipe $P_{\mathrm{T}}$ to exclude the solution flow-out to the earth's surface and deformation of the lining was taken as $P_{\mathrm{T}}=1.5 P_{\mathrm{r}}$. The mortar was injected using a constant pressure method until refusal to absorb it. The rate of the solution flow into the well was controlled using the oil pumping station to maintain the given injection pressure. In 24 hours after the injection of the mortar, the table simulator was opened, the radius of propagation of the mortar from the well $R$ and the cement layer thickness $\delta$ were measured. Based on the experiment planning methods, the same experiments were repeated 3 times to obtain a reliable result.

\section{Results and discussion}

The purpose of the experiments was to find the rational composition of the silicate cement mortar, the injection of which with the given final pressure value would make it possible to form the thickest silicate cement layer $\delta$ in the hydraulic separation crack. The fragments of the results of experimental studies are shown in Table.

The performed experimental studies have shown that for the formation of a waterproofing shell made of the silicate cement around the lining of an underground structure, the most rational composition of the silicate cement mortar is a composition with a ratio $\mathrm{C}: \mathrm{W}=1: 0.75$ with the addition of sodium silicate in an amount of $5 \%$ by weight of the cement. When this mortar was injected, the contact between the lining and the watered ground was hydraulically separated at a distance from the well of $R \geq 2,0 \mathrm{M}$ with the formation of a cement layer in a hydraulic separation crack with a thickness of $\delta \approx 5 \mathrm{~mm}$ at a distance from the well of $0,6 R$.

When injecting a thicker mortar with a ratio $\mathrm{C}: \mathrm{W}=1: 0.5$, the radius of propagation of the mortar from the well decreased. When a more liquid unstable mortar with a ratio $\mathrm{C}: \mathrm{W}=1: 1$ was injected, the mortar caused hydraulic separation along the entire length of the model and flowed out of it. At the same time, the cement layer of insignificant thickness and in the form of separate streaks was formed above the lining. A decrease in the amount of sodium silicate added to the cement mortar to 3 and $1 \%$ by weigh of the cement led to a decrease in the mortar permeability and, as a consequence, to a decrease in the radius of propagation of the mortar from the well and the thickness of the cement layer. The sodium silicate admixture in the amount of $7 \%$ turned out to be inappropriate, because after preparing such a mortar, it quickly began to lose his mobility.

Based on the analysis of the results of the performed experimental studies, a technology has been developed for the restoration of waterproofing of the used underground structure in the watered ground by the underground method. The principle of the formation of waterproofing shells around the lining of the used underground structure in the watered ground by the underground method is shown in Fig. 3.

Table. Results of experimental studies of the process of hydraulic separation of the lining from the watered ground on the experimental laboratory table simulator

\begin{tabular}{|c|c|c|c|c|c|c|c|}
\hline \multicolumn{2}{|c|}{$\begin{array}{l}\text { Silicate cement } \\
\text { mortar composi- } \\
\text { tion }\end{array}$} & \multicolumn{2}{|c|}{$\begin{array}{l}\text { Pressure, } \\
\text { MPa }\end{array}$} & \multirow{2}{*}{$\begin{array}{c}\text { Radius } \\
\text { of prop- } \\
\text { agation } \\
\text { of the } \\
\text { mortar } \\
\text { from the } \\
\text { well, } R \text {, } \\
\text { m }\end{array}$} & \multicolumn{3}{|c|}{$\begin{array}{l}\text { Cement layer thickness } \delta \\
\left(\mathrm{m} \cdot 10^{-3}\right) \text { at a distance from } \\
\text { the well: }\end{array}$} \\
\hline $\begin{array}{l}\text { Ratio, } \\
\text { C:W }\end{array}$ & $\begin{array}{l}\text { Sodium } \\
\text { silicate } \\
\text { admix- } \\
\text { ture, } \%\end{array}$ & $\begin{array}{l}\text { Ground } \\
\text { pressure } \\
\text { on the } \\
\text { lining, } P_{\Gamma}\end{array}$ & $\begin{array}{c}\text { Mortar } \\
\text { injection } \\
\text { pressure, } \\
P_{\mathrm{T}}\end{array}$ & & $0.3 R$ & $0.6 R$ & $0.9 R$ \\
\hline
\end{tabular}




\begin{tabular}{|c|c|c|c|c|c|c|c|}
\hline $1: 0.5$ & 5 & 0.2 & 0.3 & 1.53 & 7.0 & 5.1 & 3.3 \\
\hline $1: 0.5$ & 3 & 0.2 & 0.3 & 1.24 & 6.3 & 4.3 & 3.0 \\
\hline $1: 0.5$ & 1 & 0.2 & 0.3 & 0.89 & 5.8 & 4.1 & 3.0 \\
\hline $1: 075$ & 5 & 0.2 & 0.3 & 2.38 & 7.2 & 5.3 & 3.4 \\
\hline $1: 075$ & 3 & 0.2 & 0.3 & 1.56 & 6.4 & 4.3 & 3.1 \\
\hline $1: 075$ & 1 & 0.2 & 0.3 & 1.09 & 3.2 & 2.3 & 1.4 \\
\hline $1: 1$ & 5 & 0.2 & 0.3 & $>2.5$ & 2.3 & 2.0 & streaks \\
\hline $1: 1$ & 3 & 0.2 & 0.3 & $>2.5$ & 1.4 & streaks & streaks \\
\hline
\end{tabular}

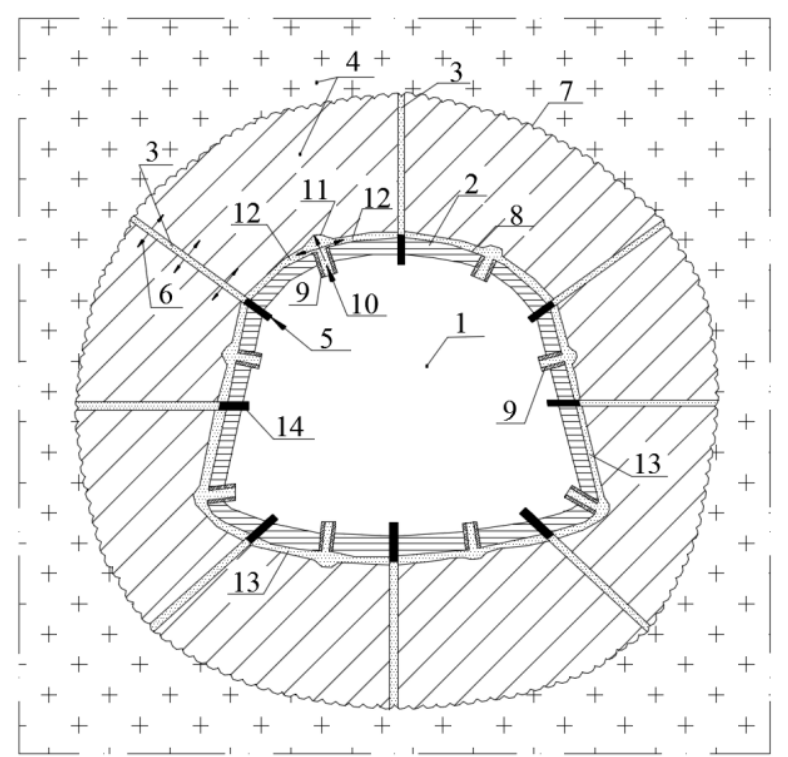

Fig. 3. Formation of waterproofing shells around the lining of the used underground structure by the underground method: 1- underground structure; 2 - lining; 3 - well; 4 - ground; 5 - cement mortar; 6 hydraulic fracture; 7 - waterproofing shell made of compacted soil; 8 - outer surface of the lining; 9 injection pipe; 10 - silicate cement mortar; 11 - incipient crack; 12 - hydraulic separation crack; 13 lower waterproofing shell made of silicate cement; 14 - injection pipe

Waterproofing of the used underground structure in the watered ground is carried out as follows (Fig. 3). The wells 3 are drilled from the underground structure 1 through its lining 2 (usually monolithic or prefabricated reinforced concrete) into the ground 4 . The cement mortar 5 is pumped through the wells 3 into the ground 4, providing its hydraulic fracturing. The cement mortar 5, propagating from the wells 3 along the hydraulic fractures 6 , compresses the ground 4 . As a result, the waterproofing shell made of compacted soil mass with artificially low water permeability 7 is formed around the underground structure 1 within the length of the wells 3 . 
After the injection of the cement mortar 5 into watered ground 4 between the wells 3 , the injection pipes 9 are installed from the underground structure 1 into the lining 2 flush with its outer surface 8 . The silicate cement mortar 10 is alternately injected into the injection pipes 9. At the same time, during the injection process, due to the pressure of the mortar on the ground, the incipient crack 11 between the outer surface of the lining 8 and ground 4 is created opposite the injection tube 9; the incipient crack 11 along the contact of the surface of the lining 8 with the ground 4 is hydraulically extended and the hydraulic separation crack 12 is filled with silicate cement mortar 10 until refusal to absorb it.

After injecting the cement mortar 5 through the wells 3 into the ground 4 providing its hydraulic fracturing 6 , the hydraulic separation of the outer surface of the lining 8 of the underground structure 1 from the ground 4 and filling the hydraulic separation cracks 12 with the silicate cement mortar 10, two waterproofing shells are formed around the underground structure 1 , the upper one 7 is made of the soil mass compacted with cementation with artificially lowered water permeability and the lower one 13 is made of the silicate cement.

The diameter of the wells 3 for the cement mortar injection 5 are $42-72 \mathrm{~mm}$. First, a through hole is drilled in the lining (usually concrete or reinforced concrete) with a diamond bit, and then a hole is drilled with a screw drill through it in the ground. The distance between the wells is taken as $2 \times 2 \mathrm{~m}$. The injection pipe 14 (injector) is embedded into the wellhead (into the lining) to inject the cement mortar. In unstable soils, instead of an injection pipe, a spacer injector with a perforated injection pipe placed in the well is installed in the lining.

The stable cement mortar with a cement-water mass ratio $\mathrm{C}: \mathrm{W}=1: 0.5$ is injected into the wells one by one until refusal to absorb it. The final pressure of injection of the cement mortar into the well $P_{\text {ск }}$ is assigned taking into account the volumetric weight of the watered ground $\rho$ above an underground structure and its depth $H$ from the expression: $P_{\mathrm{cK}}=$ $1,25 \rho \times H$. In the event of a flow-out of the cement mortar to the earth's surface, the pressure of the mortar injection is reduced

Through holes in the lining of an underground structure for injection pipes are drilled with a diamond crown (drill) with an inner diameter of 102-152 mm, since with an inner diameter of the pipes $<102 \mathrm{~mm}$, the contact area of the injected silicate cement mortar with the ground in the injection pipe may be insufficient for creating the incipient crack in the ground opposite the injection pipe, and if the inner diameter of the pipes is $>152 \mathrm{~mm}$, the bearing capacity of the lining of an underground structure will weaken and the cost of installing injection pipes into the lining will increase

The silicate cement mortar with a cement-water mass ratio $\mathrm{C}: \mathrm{W}=1: 0.75$ with the addition of sodium silicate (water glass) in the amount of $5 \%$ by weigh of the cement is injected into the injection pipes until refusal to absorb it. The final pressure of the injection of the silicate cement mortar into the injection pipe $P_{\mathrm{T}}$ is assigned taking into account the volumetric weight of the watered ground $\rho$ above an underground structure and its depth $H$ from the expression: $P_{\mathrm{T}}=1,5 \rho \times H$.

\section{Conclusion}

1. To prevent the penetration of groundwater into the used underground structure, a technology has been proposed for the formation of two waterproofing shells behind the outer surface of the lining of an underground structure: the upper one, formed by cementation of the ground around the structure with its hydraulic fracturing, and the lower one, formed of the silicate cement by hydraulic separation of the lining of the structure from the ground with the silicate cement mortar. 
2. It was experimentally established that for hydraulic separation of the lining of an underground structure from the ground, it is necessary to use the silicate cement mortar with a ratio $\mathrm{C}: \mathrm{W}=1: 0.75$ with the of sodium silicate (water glass) admixture in an amount of 5\% by weigh of the cement, the final injection pressure of the silicate cement mortar into the injection pipe must exceed the hydrostatic pressure of the watered ground on the lining by 1.5 times, and the distance between the injection pipes must be $2.0 \mathrm{~m}$.

\section{References}

1. Chang-Yu Ou. Deep Excavations (London, Taylor \& Francis, 2006)

2. E. Farrell, B. Lehane, M. Looby, Proc. Instn. Civ. Engrs., 10, 233 (1998)

3. J. Parkas, 4th Budapest Conf. on Soil Mechanics, 397 (I97I)

4. G. Y. Fenoux, S. Milanese, Gr. Engr., 5, 24 (1975)

5. R. B. Storry, Grouting and Ground Treatment: Proc. 3-rd Int. Conf., New Orleans, 342 (2003)

6. W. R. Nash, Mining Engineering, 3 (1984)

7. F. Reuter, New Mining Technology, 3, 57-61 (1983)

8. R. B. Storry, Grouting and Ground Treatment: Proc. 3-rd Int. Conf., New Orleans, 248 (2003)

9. H. Markkraf, New Mining Technology, 6, 72 (1973)

10. J. Chang, Y. C. Yortos, SPE Formation Evaluation. 1, 31 (1990)

11. Haidong Chen, Yuanping Cheng, Tingxiang Ren, Hongxing Zhou, Qingquan Liu, International Journal of Rock Mechanics and Mining Sciences, 71, 105 (2014)

12. T. D. Moore, M. Zabetakis, Bureau of mines, Report of Investigations, 7657 (1972)

13. P. R. Sheorey, M. N. Das, S. K. Bordia, B. Singh, Int. J. Min. Geol. Eng., 4, 273 (1986)

14. S. Thomson, L. Lunarzewski, Proc. Int. Conf. on Coal-Bed Methane, Katowice, 131 (1998)

15. F.D. Wang, W.A. Skelly, J. Wolgamott, Bureau of mines, Report of Investigations, 9325 (1976) 